\title{
Distâncias e Relações entre Sociedade Civil e Poder Público Local: Atuação de duas Associações de Moradores em Lavras, MG
}

Silva Andrade, Luís Fernando; Souza Oliveira, Maria de Lourdes

Distâncias e Relações entre Sociedade Civil e Poder Público Local: Atuação de duas Associações de Moradores em Lavras, MG

Administração Pública e Gestão Social, vol. 11, núm. 2, 2019

Universidade Federal de Viçosa, Brasil

Disponible en: http://www.redalyc.org/articulo.oa?id=351558326004

Esta obra está bajo una Licencia Creative Commons Atribución-NoComercial-SinDerivar 3.0 Internacional. 


\title{
Distâncias e Relações entre Sociedade Civil e Poder Público Local: Atuação de duas
} Associações de Moradores em Lavras, MG

\author{
Distances and Relations between Civil Society and Local Government: the role of two associations of residents in \\ Lavras, MG \\ Distancias y Relaciones entre Sociedad Civil y Poder Público Local: Actuación de dos Asociaciones de Vecinos en \\ Lavras, MG
}

Luis Fernando Silva Andrade

Universidade Federal de Lavras, Brasil

Redalyc: http://www.redalyc.org/articulo.oa?

Luisfernando.andrade@ufla.br

Maria de Lourdes Souza Oliveira

Universidade Federal de Lavras, Brasil

marocabj@gmail.com

id $=351558326004$

\author{
Recepción: 17 Febrero 2017 \\ Aprobación: 29 Noviembre 2017 \\ Publicación: 01 Abril 2019
}

\section{Resumen:}

Este estudio tuvo por objetivo la comprensión de la relación entre asociaciones de vecinos y el poder público local. Se buscó entender la actuación de dos asociaciones en sus respectivas comunidades y cómo influye en su organización y forma de relacionarse con otras asociaciones, organizaciones de la sociedad civil y el poder ejecutivo local. De ese modo, las motivaciones teóricas fueron la sociología relacional y la Estructura de Oportunidades Políticas. La investigación es descriptiva y tiene como instrumentos de recolección de datos entrevistas, análisis documental y observación, valiéndose del análisis temática para su interpretación. Los resultados indican una pluralidad de intereses, así como la utilización de estrategias para mantener la continuidad de las relaciones con el poder público local y la publicización de las demandas de las comunidades, incluso si recurre a una supuesta neutralidad y excesivo aprecio de oficios, mantenimiento de las mismas relaciones desde la fundación de las asociaciones.

Palabras clave: Asociativismo de Barrio, Sociedad civil, Repertorio.

\section{Resumo:}

Este estudo teve por objetivo a compreensão da relação entre associações de moradores e o poder público local. Buscou-se entender a atuação de duas associações em suas respectivas comunidades e como estas influenciam sua organização e forma de se relacionar com outras associações, organizações da sociedade civil e o poder executivo local. Desse modo, os arcabouços teóricos foram a sociologia relacional e a Estrutura de Oportunidades Políticas. A pesquisa é descritiva e tem como instrumentos de coleta de dados entrevistas, análise documental e observação, valendo-se da análise temática para sua interpretação. Os resultados indicam uma pluralidade de interesses, bem como a utilização de estratégias que visam manter a continuidade das relações com o poder público local, mesmo que recorrendo a uma suposta neutralidade e excessivo apreço de ofícios, que denotam a manutenção das mesmas relações desde a fundação das associações.

Palavras-chave: Associativismo de Bairro, Sociedade Civil, Repertórios.

\section{AbSTRACT:}

This study aimed to understand the interaction between associations of residents and the local government, seeking the comprehension of two active associations agency and how it influences their organization and how they relate with other associations, civil society organizations and local executive power. Thus, the theoretical frameworks were the relational sociology and the Structure of Political Opportunities. The research is descriptive and the data were collected through interviews, documentary analysis and observation, and interpreted through thematic analysis. The results indicated a plurality of interests, and the use of strategies to maintain relations with the local government and to reach their communities' demands, even if using a supposed neutrality and excessive appreciation of letters sent to the city hall, showing the maintenance of the same relations since the founding of associations.

KEYWORDS: Associations of residents, Civil Society, Repertoires. 


\section{INTRODUÇÃO}

Apesar de ressaltada a importância de organizações da sociedade civil para democratizar e trazer mais transparência aos processos de decisão do Estado, entre elas as associações de moradores, poucos estudos contemplam a realidade destas organizações e os contextos nos quais elas estão inseridas em municípios pequenos e médios.

Enquanto agentes locais com preocupações sobre desenvolvimento e defesa de direitos, essas associações buscam poder político ou conquista de espaço nas decisões que afetam os meios de vida de seus integrantes, em espaços participativos já delimitados, por dispositivos legais ou constrangimentos advindos do contexto político do município.

A política local desperta maior interesse com a promulgação da Constituição de 1988, no novo papel atribuído aos municípios, como entes federados autônomos. Assim, nos baseamos em estudos que tratam das relações entre atores da sociedade civil e Estado a partir da sociologia relacional (Elias, 2001, Jessop, 1982, 1985) e da Estrutura de Oportunidades Políticas - EOP (Tarrow, 1997, Tilly, 2006), partindo do pressuposto de interdependência entre indivíduos e sociedade (um não existe sem o outro). Supomos, então, uma pluralidade de indivíduos para a compreensão do fenômeno associativo no município em estudo, para os quais constrangimentos e oportunidades junto ao poder público acabam por interferir em seu padrão de atuação e originam seus repertórios de interação (Tilly, 2006).

Partindo para o objeto de estudo, Lavras, o município em que se encontram as associações estudadas, está localizado no sul do estado de Minas Gerais, na região do Campo das Vertentes, possui área de $564,5 \mathrm{~km}^{2}$ e população, em 2010, de 92.200 habitantes, com estimativa de 102.124 habitantes para 2017. O histórico de sua povoação remonta a exploração aurífera, iniciada em 1729 na área por desbravadores paulistas, aos quais posteriormente se juntaram moradores da província de Minas Gerais. Finda a exploração do ouro, os moradores dedicaram-se à agricultura e pastoreio (IBGE, 2014).

Ainda que dados da Receita Federal indiquem a existência de um número significativo de associações de defesa de direitos e desenvolvimento (ao todo 125), pouco se sabe sobre as associações de moradores de Lavras. Alencar, Murad, Lisboa, Cimino e Ribeiro (1996), quando discorrem sobre associações comunitárias de bairros periféricos do município na década de 1980, indicam a forte influência do poder público local na fundação e manutenção das mesmas, estando a participação social condicionada à elevação da capacidade de negociação e reprodução de relações de dependência e clientelistas.

O próximo estudo a tratar do associativismo em Lavras, mais de duas décadas depois, tratou do empoderamento e transformação identitária de mulheres em associações de artesanato e culinária no município (Fonseca, 2010). Todavia, a natureza das associações pesquisadas pela autora é diferente daquelas contempladas por Alencar et al.(1996) e por este estudo. Justifica-se, portanto, a realização dessa pesquisa, a partir de um componente empírico, uma vez que o tecido associativo da cidade carece de novas pesquisas, que abarquem a heterogeneidade e singularidades das organizações que o compóem.

Complementarmente, abusca por associações/associativismo de bairro realizada na Scientific Periodicals Electronic Library (SPELL) não retorna resultados, enquanto a mesma busca feita na SciELO retorna apenas os textos de Duarte (2008) e Fontes (2013), sobre o associativismo em São Paulo nas décadas de 40 e 50, centrados na relevância das Sociedades de Amigos de Bairros (SAB) e Comitês Democráticos e Populares (CDP), as quais os autores vinculam a ascensão política de Jânio Quadros, além do texto de Gohn (2010), que trata do processo de urbanização do Morumbi e da influência da sociabilidade existente nas associações de moradores de Paraisópolis na expansão e crescimento das favelas.

Justifica-se a realização da pesquisa também a partir de um componente teórico-empírico: para Cortes e Silva (2010), a compreensão da existência de interdependências entre sociedade civil, instituições e atores estatais evita o maniqueísmo, representado pelas dicotomias em atributos que seriam intrínsecos aos dois polos, sendo possível possível trazer avanços ao desenvolvimento de estudos sobre a sociedade civil. 
Neste artigo, ao tratar-se de associações de moradores, é levada em conta a complexidade do contexto político e institucional, bem como da trama de relações que esses atores específicos desenvolvem e as estratégias para atingir seus objetivos, por vezes distintas.

Diante do exposto, a questão norteadora do artigo foi: como se organizam e atuam as associações de moradores de Lavras ( $\mathrm{MG}$ ), diante de sua função de representantes dos anseios e demandas das comunidades? O objetivo geral foi compreender as relações existentes entre associações de moradores e o poder público local. Espeficamente, busca-se (a) trazer um panorama geral do associativismo de bairro no município, assim como, (b) evidenciar as relações entre sociedade civil organizada e o poder público local.

Este trabalho foi elaborado em cinco seções além dessa introdução. Primeiramente, na fundamentação teórica, são discutidas as organizações e associações presentes na sociedade civil e teorias que embasam seu estudo atualmente. Em seguida é apresentada a metodologia utilizada. A terceira parte versa sobre os resultados obtidos na pesquisa e, por fim, são trazidas as considerações finais.

\section{Sociedade Civil: Organizações e Associações}

Inicialmente, cabe problematizar a expressão "sociedade civil" e o pluralismo de concepções que carrega. Segundo Ramos (2005, p. 75), o conceito de sociedade civil carrega "uma diversidade de significados". Na tradição de estudos de ciência política, tal conceito passou por caminhos tortuosos, que remontam ao início da modernidade, variando, de acordo com o contexto histórico e social, bem como posições teóricas e formas de governo estabelecidas.

Vários filósofos políticos trataram do conceito de sociedade civil, entre eles Hobbes, Locke, Rousseau, Ferguson, Smith, Kant, Hegel, Tocqueville, Marx, Gramsci. (Gurza-Lavalle, 1999). Neste estudo, serão focados os conceitos e autores que auxiliam na compreensão do associativismo como prática que pode trazer impactos democráticos.

Ramos (2005) relaciona os estudos que tratam de capital social, engajamento cívico e em que uma esfera associacional ativa traz força e estabilidade para as democracias a uma vertente neo-tocquevilliana ${ }^{[\mathrm{i}]}$.

Putnam (1995) elucida que diversos cientistas sociais de tendência neo-tocquevilliana atribuem, por meio de evidências empíricas, que a qualidade da vida pública e o desempenho das instituições sociais são fortemente influenciados por normas e redes de engajamento cívico, não só nos Estados Unidos, mas também no Leste Asiático e na América Latina. Porém, evidências indicavam o desgaste do capital social estadunidense, refletido no declínio na participação nas eleições nacionais, bem como no número de afiliações, sejam elas sindicais, religiosas, voluntárias ou cívicas. Dessa forma, os norte-americanos estão cada vez mais jogando boliche sozinhos (bowling alone, título do famoso artigo), uma alegoria à falência da cultura associativa cívica norte-americana (Gurza-Lavalle, 1999).

A importância dada ao associativismo e do sujeito que dele faz parte e constrói a história trouxe contribuições notáveis para o entendimento das organizações da sociedade civil. Todavia, ressalvas devem ser feitas a essa vertente: muitas das características dadas a essas organizações espontâneas foram, também, utilizadas em um modelo neoliberal, que traz o conceito de Terceiro Setor, fortemente utilizado no Brasil para retratar as mudanças e esgotamentos dos movimentos sociais e expansão de organizações não governamentais. Terceiro Setor, conceito surgido nos Estados Unidos, é pautado num individualismo liberal, cuja participação nas entidades em que o compõem não afeta processos de emancipação, nem tensiona o poder constituído, mas favorece a defesa de interesses específicos de pequenos grupos, afetando a mobilização social e despolitização de organizações civis (Montaño, 2003).

Moura e Silva (2008) esclarecem que o debate internacional sobre sociedade civil, na década de 90, muito se relaciona ao fortalecimento da sociedade civil e sua a consequente emancipação, influenciada por Jean Cohen e Andrew Arato, autores que se basearam na separação entre mundo do sistema e o mundo da vida 
de Jürgen Habermas. Dessa forma, a sociedade é vista como organização que está fora do âmbito do Estado e do mercado (mundo do sistema).

Já no Brasil, Costa (1994, p. 51), baseado em Jürgen Habermas, trata da centralidade do conceito de sociedade civil, apesar de considerá-lo difuso e contraditório, para se pensar os movimentos sociais brasileiros, de modo que as associações de moradores efetivamente tematizam e publicizam demandas da esfera privada e as transportam para o domínio público, ainda que a realização desses interesses, desde os estudos de Sérgio Costa, não possa ser entendida como algo puramente benéfico à sociedade como um todo, cabendo espaço para negociações intransparentes e relações clandestinas entre associações de base comunitária e Estado.

Dagnino (2004), por sua vez, trata da confluência perversa entre o projeto político democratizante e participativo, iniciado com a Constituição de 1988, e o projeto neoliberal. Essa confluência se dá na similaridade das exigências de cada um desses projetos: tanto o projeto de alargamento da democracia, base de toda a arquitetura participativa brasileira quanto o projeto neoliberal, a partir da eleição de Collor em 1989, com o ajuste neoliberal e isenção de responsabilidades do Estado (Estado Mínimo), exigem uma sociedade civil forte e atuante, ainda que possuam fins totalmente diferenciados.

Complementarmente, Avritzer (2007) destaca que com o alargamento da presença da sociedade civil nas políticas públicas, a partir do fim do período autoritário, em 1985, possibilitou a inserção de diversas associações da sociedade civil em conselhos gestores de políticas públicas de áreas como assistência social, saúde, política urbana, educação, dentre outros. Essa inserção traz uma nova problemática da representação dentro desses espaços institucionalizados de participação e, consequentemente, de sua legitimidade, na relação entre representantes (membros de associações) e representados (comunidades ou segmentos específicos da sociedade, como mulheres, população negra, idosos, etc.).

Avritzer (2012, p. 394) considera então que, com o aprofundamento democrático, existe uma interdependência entre sociedade civil e Estado, assim, e as associações da sociedade civil podem ser consideradas semiautônomas, uma vez que mantêm "sua própria dinâmica organizacional e o seu próprio processo de tomada de decisão" quando se relacionam com o Estado e publicizam as demandas de seus representados.

Gurza-Lavalle (1999), em sua crítica à nova sociedade civil, apresenta a contradição entre o bowling alone de Putnam e a ressurreição da sociedade civil na década de 1990, com claras consequências democratizadoras. Também diz que autores na época desconsideram a longa tradição conceitual da sociedade civil. Percebe-se, então, o abandono da premissa do vínculo constitutivo entre sociedade e Estado, restabelecendo apenas uma relação externa dicotomizada, em que a primeira representa o polo positivo, protagonista de um constante conflito com o segundo, o polo negativo e antagonista.

Como possibilidade de saída de caracterizações unificadoras e homogeneizadoras da sociedade civil, estudos mais recentes utilizam-se da sociologia relacional, dando atenção às relações existentes em uma sociedade civil e Estado heterogêneos, repletos de interesses diversos, pluralidade e particularidades. Trazem também contribuições da análise de redes sociais, assumindo a premissa de que os laços (entre indivíduos e atores coletivos) são elementos estruturantes da vida social, gerando possibilidades e restrições para a ação. Desse modo, o detalhamento desses vínculos laços é importante, uma vez que moldam o funcionamento das instituições e da própria sociedade civil (Baiocchi, Heller, \& Silva, 2008).

Conforme apresentado por Marques (2007), a sociologia relacional surge de um programa de pesquisas da década de 1970 que foca na análise de padrões de relações de indivíduos e entidades inseridos em determinados contextos sociais. Assim, a construção de redes em que atores mantêm vínculos diversos é uma tentativa de construir um nível analítico entre estrutura e ação social.

De modo semelhante, Cortes e Silva (2010), ao tratarem de teorias nas quais é ressaltada a interdependência entre sociedade e Estado, trazem a discussão acerca da perspectiva estratégico-relacional, de Bob Jessop, o qual argumenta que: 
“[...] os poderes e as capacidades estatais não podem ser compreendidos focalizando o Estado isoladamente. A análise deve considerar também o contexto estratégico relacional. Para ele [Bob Jessop], em função de sua seletividade estrutural e de suas capacidades estratégicas específicas, o poder estatal é sempre condicional e relacional.” (Cortes, \& Silva, 2010, p. 433).

Dias (2009) retrata que Jessop aproximou-se da linha marxista por meio de dois autores: Gramsci e Althusser. Essas influências foram sintetizadas pelo teórico grego Nicos Poulantzas, que utilizou-se de uma noção de poder relacional para compreender como as classes sociais se organizavam em Estados burgueses, a fim de conseguir hegemonia. Para Poulantzas, o próprio Estado é uma relação social, excluindo seu entendimento como sujeito (Jessop, 1985).

Jessop (1982) destaca que uma das dificuldades da análise social é distinguir entre estrutura e prática, estrutura e conjuntura ou estrutura e processo. O autor postula coloca que uma forma de solução para esse problema é o reconhecimento de que a estrutura deve ser definida em termos relacionais, para, assim, distinguir entre momentos estruturais e momentos conjunturais.

O momento estrutural, de acordo com Jessop (1982), pode ser definido como aquele em que elementos que compõem a formação social não podem ser alterados por um dado agente. Já o momento conjuntural representa elementos que podem ser mudados por um agente (ou um grupo de agentes), o que traz implicações importantes para a análise social: elementos podem funcionar como "constrangimentos estruturais" para certos atores, enquanto podem aparecer como "elemento conjuntural” para outros, passível de transformação, que podem tornar-se uma "oportunidade conjuntural”.

Essa abordagem ressalta a importância de vínculos e alianças estratégicas e táticas na luta para transformar determinadas situações ou conjunturas e define limitações para o uso do conceito "poder", que não pode ser dado a priori e sim, visto como uma complexa relação social que reflete as mudanças no equilíbrio de forças em determinada situação. Jessop (1982, p. 253, tradução nossa), então, conceitua poder como "produção de efeitos dentro de limites fixados por 'constrangimentos estruturais' enfrentados por diferentes agentes”. $\mathrm{O}$ autor ainda considera que a política é a arte do possível: mesmo que o poder não seja puramente um choque de vontades, ele "tem condições materiais de existência definitivas e é circunscrito por meio de suas ligações com outras determinações da formação social” (Jessop, 1982, p. 255, tradução nossa).

Tal reflexão traz à tona o conceito de interesse. Em uma perspectiva relacional, ele é mais voltado para o alcance de vantagem comparativa em determinada conjuntura do que para um interesse absoluto e isolado das situações. Assim, situações, ações e eventos podem ser ditos de interesse de um agente se eles fazem com que tragam benefícios para a realização de suas condições de existência, dadas as restrições estruturais do contexto.

Outra abordagem utilizada em estudos brasileiros recentes (Abers e Bülow, 2011; Abers, Serafim e Tatagiba, 2014; Cortes e Silva, 2010) é a EOP, que, conforme apresentado por Cortes e Silva (2010, p. 434), preza pela forma como os atores se relacionam entre si e com o Estado, em um "contexto estratégico relacional". Surgido na década de 1970 70, o conceito de EOP se contrapôs à corrente hegemônica das Ciências Sociais por não gerar uma dicotomia entre "os processos políticos institucionais e não institucionais", atentando-se para processos organizativos e mobilização política de atores dos movimentos sociais e do sistema político-administrativo.

Autores como McAdam, Charles Tilly e Sidney Tarrow, indo contra essa separação, argumentam que processos institucionais e não institucionais estão intimamente ligados e só podem ser entendidos, por meio de uma nova perspectiva de análise, o Modelo do Processo Político (Cortes e Silva, 2010). Segundo os autores, nesse neste modelo a configuração político-institucional molda uma estrutura de oportunidades políticas para a ação dos atores sociais, seja por meio de constrangimentos ou criação de incentivos, daí decorre a definição de regime e como ele afeta os atores sociais:

Qualquer regime, de acordo com análises de EOP, cria um ambiente específico de oportunidades e ameaças políticas ao qual os demandantes necessariamente respondem. Alterações nesse ambiente, prossegue o argumento, produzem mudanças na contenção. Podemos incluir em análises de EOP (a) a multiplicidade de centros de poder independentes dentro do regime, (b) a abertura do regime a novos atores, (c) a instabilidade 
dos alinhamentos políticos atuais, (d) a disponibilidade de aliados ou apoiadores influentes, (e) a medida que o regime reprime ou facilita a construção coletiva de reivindicações, e (f) mudanças decisivas nos itens de a a e. (Tilly, 2006, p.43-44, tradução nossa).

Os atores, por sua vez, interpretam as oportunidades e constrangimentos estipulados pelo regime e de acordo com os recursos políticos que possuem para nele intervir. Ocorre dessa forma a construção de padrões de organização social, denominados repertórios:

\footnotetext{
"Repertórios variam de lugar para lugar, tempo e par a par. Mas, no geral, quando as pessoas fazem reivindicações coletivas, eles inovam dentro dos limites estabelecidos pelo repertório já delimitado estabelecido para o seu lugar, tempo e par. Assim, ativistas de movimentos sociais nas cidades europeias de hoje adotam uma mistura de reuniões públicas, declarações à imprensa, manifestações e petições, mas ficar longe atentados com bombas, sequestros, e autoimolação. O seu repertório baseia-se em uma longa história de lutas anteriores." (Tilly, 2006, p. 35, tradução nossa).
}

Para Tarrow (1997), a ação coletiva surge em resposta a mudanças na estrutura de oportunidades e restrições políticas. Valendo-se de repertórios de ação já conhecidos, os participantes dessas ações respondem a uma variedade de incentivos: "materiais, ideológicos, partidaristas, grupais, prolongados ou esporádicos" (Tarrow, 1997, p. 33).

Charles Tilly e Sidney Tarrow trabalham, principalmente, com o conceito de repertórios de contenção, envolto em contextos de conflito entre sociedade civil e Estado. Abers, Serafim e Tatagiba (2014) basearamse nos repertórios de contenção para desenvolver o conceito de repertório de interação. A diferença fundamental reside no fato que, na concepção das autoras, é possível que o Estado inicie tais repertórios, e que as dinâmicas sejam colaborativas (Abers, Serafim, \&Tatagiba, 2014).

As autoras trazem quatro repertórios de interação que os movimentos sociais brasileiros utilizam em suas negociações com o Estado e em suas ações que podem partir 'de dentro' do Estado: (i) protesto e ação direta; (ii) participação institucionalizada; (iii) política de proximidade; e (iv) ocupação de cargos na burocracia, os quais podem ser combinados ou transformados de acordo com o regime.

Abers, Serafim e Tatagiba (2014) evidenciam que a interação sociedade-Estado constrói possibilidades e que a escolha por determinado repertório deriva da situação atual/contexto político, bem como de um cálculo estratégico (quem ganha e quem perde) do uso de espaços participativos. Dessa forma, o 'momento' tem grande influência na escolha e combinação de repertórios de interação, desde uma participação mais direta até uma totalmente institucionalizada (e todo um gradiente de opções dentre estas duas possibilidades extremas). Evidencia-se então que, em estudos recentes como esse, o consenso em torno de categorias analíticas principais carece de mais estudos empíricos, com grande poder de explicação, mesmo que a capacidade de generalização seja reduzida.

Dessa forma, tanto a perspectiva estratégica-relacional de Bob Jessop, quanto a estrutura de oportunidades políticas, discutida por Sidney Tarrow e Charles Tilly, podem contribuir para o entendimento da relação entre sociedade civil e Estado, neste estudo, associações de moradores e poder público local.

Conforme apresentado por Cortes e Silva (2010), as perspectivas analíticas que melhor se adequam para captar a complexidade de processos sociais são aquelas que conseguem abarcar duas dimensões: a estrutura política que, em sua configuração, determina constrangimentos e oportunidades, mas também a capacidade reflexiva dos atores, que realizam cálculos estratégicos de acordo com o contexto em que estão inseridos.

\section{Metodologia de pesouisa}

O presente estudo é caracterizado como descritivo e qualitativo. Para a coleta de dados foram utilizadas as técnicas pesquisa documental, observação e entrevistas. A pesquisa documental foi feita a partir de dados da Receita Federal, por meio do Portal da Transparência (CGU, 2014), a fim de atualizar as informações existentes sobre as associações no município estudado (IBGE, 2004, 2008, 2012). A partir desses dados, foi 
feito contato por meio dos endereços registrados. A observação (feita em 6 reuniões) e as entrevistas por pautas ( 4 em cada associação e uma com um jornalista da mídia local) foram realizadas entre novembro e dezembro de 2014. As associações pesquisadas, formais e atuantes, serão doravante denominadas Associação 01 (os bairros Vale do Sol e Vila Rica II) e Associação 02 (Jardim Glória, Jardim Campestre I, II e III). O detalhamento é feito na figura 1 .

Figura 1 - Instrumentos de Coleta

\begin{tabular}{|c|c|c|}
\hline Instrumento & Fonte de Dados & Descrição \\
\hline Pesquisa Documental & $\begin{array}{l}\text { Portal da } \\
\text { Transparência, } \\
\text { CGU }\end{array}$ & $\begin{array}{l}\text { Dados do } \\
\text { Cadastro da } \\
\text { Relação Anual de } \\
\text { Informações } \\
\text { Sociais - RAIs }\end{array}$ \\
\hline \multirow[t]{2}{*}{ Observação } & Associação 01 & - \\
\hline & Associação 02 & $\begin{array}{l}\text { Participação em } 6 \\
\text { reuniôes entre } \\
\text { novembro e } \\
\text { dezembro. }\end{array}$ \\
\hline \multirow[t]{3}{*}{ Entrevistas } & Associação 01 & $\begin{array}{l}\text { Entrevistas } \\
\text { semiestruturadas } \\
\text { E1A, E1B, E1C, } \\
\text { E1D }\end{array}$ \\
\hline & Associação 02 & $\begin{array}{l}\text { Entrevistas } \\
\text { semiestruturadas } \\
\text { E2A, E2B, E2C, } \\
\text { E2D }\end{array}$ \\
\hline & Jornalista & EJ \\
\hline
\end{tabular}

A análise das entrevistas foi feita via análise temática (Bardin, 2002, Braun \& Clark, 2006)), utilizando uma grade aberta. A primeira etapa, de (i) familiarização, consistiu na leitura dos textos das entrevistas e das notas de campo da observação realizada; a (ii) a geração de códigos e sistematização dos dados se deu pela separação dos conteúdos de acordo com sua origem e iniciou-se a busca por relações entre as falas proferidas pelos diferentes entrevistados, tanto nas entrevistas quanto nas reuniões em que foi feita a observação; (iii) o mapeamento, classificação e agrupamento dos temas a partir da organização prévia dos dados gerou três temas centrais para a discussão: o apartidarismo das associações, experiências prévias de participação e formalismo na relação entre sociedade civil e Estado. (iv) A revisão dos temas, de suas relações e contradições levou à etapa final de (v) definição da categoria central de análise, chamada estratégias de autonomia, por entender-se que a busca por uma distinção clara entre as associações e o poder público e o uso do formalismo são recorrentes na atuação dessas organizações, balizados pela experiência prévia dos membros das associações e pela visão negativa que possuíam da política pública local.

\section{Associativismo de Bairro em LaVras: caracterizaÇÃo E RELAÇões}

De acordo com dados da Receita Federal, em março de 2014 havia o registro de 638 associações privadas, entre elas, 409 com registro ativo, 221 baixados, 1 registro nulo e 7 suspensos. Do total, 125 unidades são associações de defesa de direitos.

Dentre as associações de defesa de direitos e desenvolvimento, é oportuno verificar o quantitativo de associações ao longo dos anos, o que é demonstrado na figura 1. Destaca-se 2001, ano no qual houve o maior incremento, 12 associações, sendo 5 delas associações de bairro e 6 de comunidades rurais. Já em 2006 também houve incremento de 9 associações, 3 delas associações de bairro. O ano de 2008 se destaca pela redução no número de associações (23), esse número é justificado pela remissão da dívida destas organizações, que 
levou ao fechamento do cadastro. Não é possível precisar, mas em virtude da forma como foram encerradas, é possível inferir que várias associações já não estavam mais atuantes ou não declaravam a RAIS.

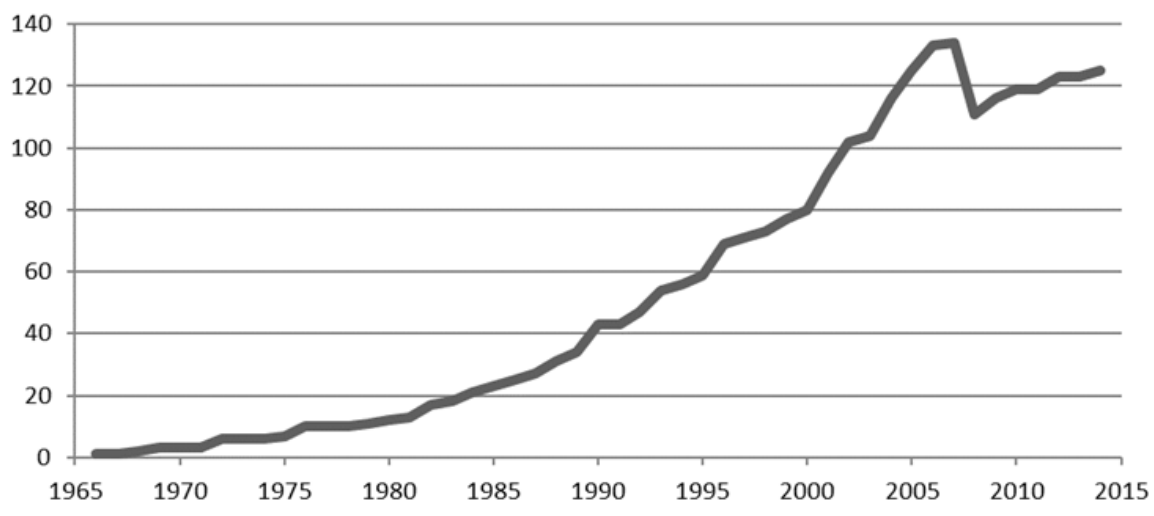

Figura 2 - Número de Associações de Defesa de Direitos em Lavras-MG, por Ano Fonte: elaborado pelo autor a partir de dados da CGU (2014).

Existem, 16 registros ativos de associações de bairro no município, as informações obtidas na observação de reunióes confirmaram que há outra associação de bairro, formalizada no Bairro Novo Horizonte e que associações de bairro informais atuam nos bairros Dona Wanda, Serra Verde e COHAB.

Quanto às associações formais, do total de 17, apenas 4, de acordo com as informações disponibilizadas pelos entrevistados, são atuantes em suas respectivas comunidades, deixando claro as limitações dos dados cadastrais da Receita Federal. De toda forma, essas informações tem relevância, uma vez que mostram a distância existente entre as associações que instituídas formalmente e as que são atuantes na prática.

Nas duas associações estudadas em profundidade, nota-se que são constituídas por pequenos grupos (geralmente entre 4 e 5 pessoas), sendo notável a ausência de jovens em ambas. As associaçóes, por meio de seus membros, realizam ligações com diversas outros agentes, tanto da sociedade civil quanto do poder público local e de representações políticas. $\mathrm{Na}$ associação 01 verifica-se a importância da militância de alguns de seus membros, tanto em partidos políticos quanto em sindicatos, além do movimento feminista e movimento negro.

$\mathrm{Na}$ associação 02 percebe-se maior vinculação com espaços de participação institucionalizada, como Conselhos e Comitês, bem como de empresas que patrocinam o jornal da associação, de circulação mensal. A relação com o Ministério Público vincula-se aos problemas enfrentados pela comunidade do bairro Jardim Campestre III, em que o Grupo SN realiza a extração de granito próximo ao bairro. A ligação com a Polícia Militar (PM-MG) se dá por meio do projeto Rede de Vizinhos Protegidos.

Outra questão importante a ser descrita é a relação entre associação de moradores e poder público local, uma vez que a mediação dos interesses da comunidade é tida como a função mais importante da organização. Percebe-se na fala dos entrevistados que a atuação da associação é fortemente influenciada pela abertura dada pelo poder público, ou seja, restrições e contingências existem de acordo com a atenção dada às entidades representativas dos bairros. Cabe ressaltar ainda que a representação da comunidade perante o poder público se dá por meio de negociações e, mesmo que seus membros sejam ouvidos, não há garantia de atendimento das demandas.

Dado esse contexto de abertura, nota-se que, após um período de boas relações entre a Associação 01 e o Poder Público Local, durante o mandato de 2001 a 2004 de um prefeito do Partido Progressista (PP), durante os 8 anos seguintes (dois mandatos de uma prefeita do Partido da Social Democracia Brasileira - PSDB), a Associação teve dificuldades em se relacionar com o poder público, uma vez que, em razão da proximidade no período anterior, foi creditada à associação um vínculo político com o ex-prefeito do PP. 
$\mathrm{Na}$ Associação 02, como também notado no primeiro caso, a atuação da associação é influenciada pela abertura dada pelo poder público local para as negociações. Da mesma forma, o contexto político influencia a possibilidade e a continuação de projetos. Um exemplo muito claro é a negociação para a implantação de um parque ecológico nos bairros, afetada pela cassação do prefeito e posse de um novo em setembro de 2014. Os prejuízos para a retomada do projeto não se referem apenas às negociações perdidas, mas também ao fato de, muitas vezes, um prefeito não querer continuar projetos tidos como de outro.

Um ponto comum é que as duas associações participaram de um projeto, iniciado em 2013, para a criação de uma Liga de Associações no município. Os entrevistados relatam que o projeto era coordenado por um integrante da associação do bairro Cruzeiro do Sul, a qual, segundo os dados obtidos, não se encontra mais atuante e visava reunir as associações para obter maior representação política e contribuir para a formalização das associações envolvidas no projeto. Percebe-se então que, mesmo ligando diversos atores, os vínculos entre as próprias associações de moradores são praticamente inexistentes: mesmo sabendo da existência das demais, a atuação em conjunto, como preconizava a iniciativa da Liga de Associações, não ocorre.

\subsection{Resultados}

É ressaltado na teoria de Estado de Jessop (1982), e também é notado nas entrevistas realizadas, que os interesses dos agentes, sejam individuais ou coletivos, são diversos e podem ser contraditórios, diante de um contexto que impóe constrangimentos estruturais que possui elementos conjunturais que podem ser transformados em oportunidades. Assim, por meio da interpretação da situação e histórico de ações, os atores envolvidos criam seus repertórios, os quais guiam suas ações, em um cálculo estratégico de suas ações.

Percebe-se, nas associações estudadas, que os interesses do pequeno grupo que as compõem são diversos. Esses interesses, apresentados por Jessop (1982) na perspectiva relacional como alcance de vantagem competitiva em determinada conjuntura, apresentam diferenças de conteúdo para cada sujeito que toma parte nas associações de bairro estudadas, fato semelhante àquele presente nas diferenças de conteúdos dos repertórios, uma consequência lógica ao se pensar que os membros dessas organizações realizam ações calculadas estrategicamente, ao analisar-se o que se ganha e o que se perde com determinada ação.

A pluralidade de interesses é vista nas associações estudadas como possibilidade de trazer dinamismo para sua atuação, bem como gerar entraves. O dinamismo é visto por meio das múltiplas ligações e frentes de ação criadas na rede de atuação das associações de bairro, já os entraves relacionam-se a interesses particulares que divergem daquilo que é estipulado como finalidade das organizações estudadas, ou que, se concretizados, prejudicam a imagem e as ações das associações.

Cabe destacar que a variedade de interesses existentes deriva também da diversidade de experiências e conhecimentos que os associados detêm e é notável a formação política de alguns membros das associações, que possuem experiência de militância em partidos políticos, bem como atuação em movimentos sociais e conselhos gestores de políticas públicas:

“[...] nem todo grupo presente na associação entende que a associação é uma entidade mais política que qualquer outra coisa, muitos acham que a associação é pra fazer algum servicinho no bairro, 'né', então isso, essa visão atrapalha um pouco o papel político da associação no meu entendimento. Uma outra coisa que eu percebo é que os que ficam e atuam são os que normalmente já atuam em outros grupos do movimento social, hoje por exemplo, os mais lá, um é sindicalista, o outro foi sindicalista" (E1D, grifo nosso).

Nesse sentido, as experiências participativas dos associados, ou a construção histórica de sua participação, influencia sua sensibilidade e atuação para demandas específicas da comunidade. Por exemplo, membros da Associação 01, que participam de partidos políticos, sindicatos e movimentos sociais são incumbidos de negociar, quando necessário, com os gestores públicos. 
Já na Associação 02, os associados que apresentam histórico de luta por questões ambientais no município se envolvem mais na criação do parque ecológico e na coleta de assinaturas para o abaixo-assinado referente à atuação da pedreira no município. Outro membro, com ampla experiência em participação no setor da saúde, é mais sensível a essas demandas da comunidade e possui conhecimento amplo sobre o setor e suas instituições. Da mesma forma, aqueles com experiência em ações voluntárias de integração social atuam com grande dedicação nos eventos das associações, vistos como formas de estreitar os laços comunitários, resgatar a história e promover cultura.

A diversidade de construções histórico-políticas e a pluralidade de interesses dos sujeitos que tomam parte nas associações fazem também com que as associações apresentem características únicas, bem como repertórios, padróes históricos de atuação, variados e com conteúdos distintos.

Jessop (1982) ressalta que os interesses dos atores devem ser considerados a partir dos constrangimentos estruturais e oportunidades conjunturais de determinado período e que podem ocorrer conflitos de interesse em determinadas situações e ações.

As experiências participativas e os interesses plurais afetam a forma como os constrangimentos estruturais e oportunidades conjunturais são interpretados pelos associados. O padrão histórico de atuação das associações, frente ao poder público, repertório, é construído com base nessas experiências, interesses e limitações impostas.

Cabe também discutir o padrão histórico de atuação das associações, levando em conta a pluralidade de interesses e experiências participativas existentes. Considerando que os atores envolvidos em determinado regime interpretam as oportunidades conjunturais e constrangimentos estruturais presentes em seu contexto de atuação frente ao Estado e que eles se valem de seus interesses, busca-se nessa categoria compreender os repertórios, padrões históricos de ação, dessas organizações.

São evidentes, nas entrevistas realizadas, documentos analisados, bem como nas reuniões em que foi feita observação, que os associados agem de forma a "não tomar partido", ou seja, não se aliarem a partidos políticos. Em ambas as associações, figura nos estatutos sociais o necessário afastamento de questões políticopartidárias. A Associação 02, inclusive, possui um capítulo inteiro em seu estatuto social dedicado a esclarecimentos sobre as relações com os poderes constituídos.

Dessa forma, busca-se evitar, segundo os entrevistados, que interesses particulares ou de cunho partidário sejam colocados acima dos interesses da associação e da comunidade que ela representa. Tal perspectiva é reforçada pela existência de práticas clientelistas e de patronagem no município. Os entrevistados ainda relatam que a relação com o poder público, se não marcada por partidarismo, é de difícil realização. A ação coletiva é vista como uma saída para essa situação.

O contexto político do município traz restrições à ação das associações. Entende-se que a escolha por não se utilizar de relações político-partidárias parte de uma reflexão desses atores sobre seus interesses é um cálculo estratégico. Diante de regimes que impõem constrangimentos e restrições, Jessop (1982) afirma que os atores podem abrir mão de determinados interesses se visualizam que vantagens comparativas maiores podem ser alcançadas em longo prazo, ou que a defesa de determinados interesses em curto prazo possam afetar outros interesses em longo prazo, na relação entre conjuntura e estrutura:

“[... porque se uma associação ela é ligada à um partido político ela fica amarrada, ela fica amarrada e até as vezes, quando esse partido político está no poder, a associação tem até alguns benefícios, mas se o poder público perde e vem outro prefeito, você tá (sic) ferrado" (E1A).

Dessa forma, os atores, que são reflexivos e criam padrões históricos de atuação, os repertórios. Tilly (1992 apud Abers, Serafim e Tatagiba, 2014, p. 330) traz que repertório é "um conjunto limitado de rotinas que são aprendidas, compartilhadas e executadas através de um processo relativamente deliberado de escolha". Esses repertórios, na literatura internacional, destacam o caráter contencioso dos movimentos sociais em relação ao Estado. Já no Brasil, é importante destacar não apenas a presença de movimentos sociais dentro do Estado, 
mas também a forte interação entre sociedade civil e Estado (Abers, Serafim e Tatagiba, 2014), como acontece nas associações estudadas.

Baseado nas falas dos entrevistados, observa-se que a opção por utilizar ofícios e buscar uma suposta neutralidade traz como principal repertório, de acordo com Abers, Serafim e Tatagiba (2014), uma 'política de proximidade', na percepção dos associados, evita-se a manutenção de laços clientelistas, lobbies, troca de favores e relações personalistas:

“[...] quando eu fui coordenador [geral], quando a Associação foi iniciada, todos os ofícios, isso até agora, os ofícios são protocolados em duas vias, [...]. A gente praticamente exigia que fosse feito, que aquilo é um direito da gente. A gente paga muito imposto. Esse 'jeitinho', 'bater nas costas', 'quebra o galho', nunca. A gente até hoje mantém essa conduta” (E2B).

Conforme apresentado por Amâncio (2013), a trajetória dos atores, bem como sua inserção em redes de relacionamento, interferem no conteúdo de um repertório. A forma como as associações se relacionam com o poder público é pautada na transparência das ações e na formalização das demandas apresentadas (via ofícios que são protocolados e posteriormente apresentados à comunidade), visando à manutenção das negociações com os gestores públicos, independente do partido político que está no poder e a legitimidade de suas ações perante a comunidade.

A Associação 02 ainda possui o título de utilidade pública municipal, outorgada logo no início de sua atuação, o que evidencia a importância do caráter formal na relação entre a organização da sociedade civil e o Estado.

Opta-se, então, por denominar esse repertório, percebido nas duas associações pesquisadas, de 'Estratégia de Autonomia', uma vez que os atores sociais envolvidos buscam proximidade dos gestores públicos e relativa distância de questões político-partidárias, que podem, futuramente, prejudicar sua atuação.

A proximidade é qualificada e possui características distintas do que trata a literatura. $\mathrm{O}$ afastamento é então apresentado como forma de salvaguardar os interesses das associações e das comunidades por ela representadas. Esse tem sido o modus operandi dessas associações, na relação com a Prefeitura do município, desde suas respectivas fundações. O que evidencia incapacidade de alterar as relações com o poder público na existência da necessidade de ofícios para que a prefeitura atue nas comunidades.

\section{Considerações Finais}

A busca por compreender as relações existentes entre associações de moradores e demais atores da sociedade civil e poder público local norteou este estudo. Os resultados alcançados indicam pontos de reflexão interessantes sobre as dinâmicas e estratégias utilizadas pelas associações de moradores.

Primeiramente, com relação à pesquisa com dados secundários, percebe-se que os dados obtidos na Receita Federal e, consequentemente, as informações descritas nas publicações do IBGE sobre as FASFIL (IBGE, 2004, 2008, 2012), apresentam várias classificações problemáticas. O motivo central é que o registro do CNPJ e das atividades primárias e secundárias das associações privadas apresenta inconsistências, como organizações religiosas que têm como atividade principal atividades associativas culturais, ou ainda associações de atividades recreativas que são registradas tendo como atividade primária a defesa de direitos sociais.

Portanto, esses dados, mesmo que importantes para a condução desta pesquisa, ao revelar uma série de atores que poderiam ser pesquisados, também apresentam limitações de análise para a realização de mapeamentos. Deixando claro que as organizações formais lá apresentadas não resumem o tecido associativo existente, é apenas um retrato da condição das organizações formalizadas, lembrando que existem várias associações informais, sem registro na Receita Federal, que atuam nos bairros, conforme indicam as entrevistas e a observação realizada nas reuniões. 
É evidente, também, que grande parte das associações de bairro registradas não estão atuantes em seus respectivos bairros. Observa-se que, ao serem desativadas, não se faz um processo de liquidação e nem mesmo procura-se dar baixa no registro feito. Conclui-se, então, sobre a caracterização, que os dados são limitados por não considerarem as organizações informais e, também, por não trazerem clareza sobre quais associações são atuantes ou não. Buscou-se, então, traçar um comparativo entre o formalismo e a atuação dessas organizações.

Quanto aos dois casos estudados, alguns pontos merecem destaque. Primeiramente, o contexto e motivação de criação das associações pesquisadas: diferente daqueles encontrados por Alencar et al. (1996) em associações comunitárias de bairros periféricos, criadas na década de 80 , as duas associações estudadas foram criadas a partir de membros de suas próprias comunidades, em razão de carências existentes e necessidade de uma representação diante do poder público e não por meio de políticos locais.

Fica evidente também a pluralidade de experiências em coletivos que os membros mais atuantes das associações possuem. Em ambos os casos são pequenos grupos, que, em sua totalidade, tomam parte de diversas instâncias participativas, como conselhos, comitês, sindicatos, partidos políticos e grupos religiosos, dentre outras associações. Neste trabalho, relaciona-se essas experiências à percepção ou entendimento do que vem a ser uma associação de moradores, moldando interesses e forma de ação de seus membros.

Essa diversidade encontrada, aqui compreendida como variedade ou pluralidade de interesses, possibilita que as associações estudadas trabalhem em diversas frentes, favorecendo sua atuação e comunicação com a comunidade. Nessa pluralidade, considera-se que os membros da Associação desenvolvem uma rede de relações, de acordo com suas experiências e conhecimentos e, também, de acordo com os limites impostos pelo ambiente institucional.

Nos dois casos estudados, mesmo levando em conta as diferenças existentes entre as comunidades estudadas, fica evidente que o modus operandi de ambas as associações é semelhante quanto à mediação dos interesses dos moradores, por meio de ofícios enviados às secretarias municipais e, também, a busca de transparência nas ações por meio da distribuição de informativos e/ou boletins, uma forma de conseguir a legitimidade e o reconhecimento da comunidade.

Em sua relação com o poder público, as associações estudadas querem ocupar um espaço que, segundo a Constituição, pertence a: o exercício de uma democracia direta, uma participação que signifique partilha de poder. Logo, elas mantêm vínculos, mais ou menos estreitos, com diversas organizações sociais e órgãos públicos, abrindo um leque de possibilidades maior de atuação.

Percebe-se claramente, nos resultados apontados, que existe esforço para ocupação do espaço público e esforço ainda maior para não serem consideradas parte do sistema político-partidário, termos como "não levantar bandeira", "não tomar partido", "não escolher um lado", "ser apolítico" são frequentes nas falas dos membros da associação e também estão presentes nos estatutos sociais dessas organizações, que coíbem a utilização de sua imagem e de suas ações para a promoção político-partidária. A importância dos partidos políticos deve ser considerada como forma de dinamizar e dar voz a movimentos sociais, quando abertura é fornecida nesses espaços. Assim, os coletivos associativos marginais teriam uma possibilidade a mais de fortalecimento político e consequente visibilidade de demandas.

Existe, nas considerações dos membros das associações pesquisadas, uma suposta neutralidade humana, uma tentativa de separação de aspectos da vida cotidiana que dificilmente logra êxito: interesses e motivações de cunho político e religioso.

O receio dos associados reside, no primeiro caso, nas dificuldades apresentadas, por terem sido considerados como apoiadores de um ex-prefeito e, no segundo caso, pela descontinuidade das ações da associação frente a problemas oriundos de interesses político-partidários, que ainda acarretam dificuldades na representação da comunidade, como relatado pelos entrevistados.

Cabe lembrar que política partidária é uma parte de um todo maior que é a política. Como apresentado por um dos entrevistados, é necessário reconhecer que as associações de moradores são, em seu âmago, políticas. Esse reconhecimento pode, inclusive, favorecer a representação feita pelas associações, ao deixar bem claro 
para que finalidade foram constituídas, quais ações realizam e quais os propósitos de cada ação. Assim, evitamse confusões quanto aos objetivos e os meios para atingi-los, como nos relatos em que os moradores não sabem as reais funções da associação, confundindo-as com instituições beneficentes ou ainda como forma de "conseguir dinheiro público".

Percebe-se aí a existência de um ideário de participação nas falas dos entrevistados, tratando a comunidade, muitas vezes, como politicamente apática, ou interessada em benefícios sem ter que por eles lutar. Nesta pesquisa, considera-se o pressuposto de que a participação popular é condicionada por eventos específicos que causam grande motivação ou representam grandes interesses da comunidade, como as questões de segurança da população, como a criação da Rede de Vizinhos Protegidos, implantada no bairro representado pela Associação 01 e em vias de implantação em um dos bairros representados pela Associação 02, bem como a atuação da Associação 02 em colher assinaturas e participar de reuniões do Ministério Público sobre os incidentes e problemas ocasionados pela atuação de empresa mineradora nos bairros.

Da mesma forma, a atuação das associações é limitada pela abertura propiciada pelos gestores públicos: ocorrem restrições que influenciam a forma como as associações atuam. Em busca de autonomia, os associados fazem uso de práticas formais, representadas pelo envio de ofícios para os gestores municipais. Assim, ocupam um espaço e buscam dar voz às demandas locais, sem recorrer a práticas e relações clientelistas, que, conforme exposto pelos entrevistados, são soluções paliativas, que, na ocasião de novas eleições e de mudança de poder, são encerradas e ainda prejudicam o relacionamento com os gestores do novo mandato. Portanto, busca-se uma proximidade do poder público local, como gestor municipal e um afastamento dos aspectos políticopartidários.

A busca por maior participação da comunidade, inclusive, dos jovens e adultos jovens, praticamente ausentes do quadro de cargos, evidencia não apenas a melhoria na qualidade da participação, mas na sobrevivência e continuidade dessas organizações. As estratégias das associações, focadas na mediação com o poder público via o poder do ofício poderiam focar a renovação constante dos participantes, de diferentes faixas etárias e também o fortalecimento e divulgação das ideias da comunidade, para que estas não sejam consideradas ideias de políticos locais e abandonadas em outros mandatos.

Os impactos democráticos apresentados na literatura, tanto para os conceitos de movimentos sociais quanto para sociedade civil, apresentam-se de forma vestigial na realidade pesquisada. As ações das duas associações citadas, conforme apresentado na relação entre associação e poder público, não indicam mudanças na atuação do poder público ou na relação associação/poder público: o uso de ofícios é feito desde a fundação das associações, os quais são ditos necessários para que a prefeitura atenda a qualquer problema da comunidade.

Um impacto democrático da atuação das associações é a publicização das demandas das comunidades representadas, mesmo que a forma que elas são divulgadas indique falta de planejamento do Executivo para atender as demandas constantes das comunidades representadas. As reivindicações são repassadas e depois ocorre retroalimentação da associação para a comunidade, via informativos e boletins.

Deste modo, as principais contribuições desta pesquisa são a evidência de pluralidade de interesses existentes dentro das associações, que propiciam uma rede de relações mais diversificada e as estratégias utilizadas perante o poder público e a comunidade, para garantir um processo de negociação contínuo com o poder público e transparência nas ações para manter a legitimidade da associação perante seus representados.

Quanto às limitações deste estudo, elas são referentes principalmente à obtenção de dados secundários, que apresentam inconsistências na classificação das associações e, mesmo fornecendo indícios para a pesquisa de campo, são limitados para tratar das associações que atuam nos bairros.

Outra limitação é a pesquisa ter sido feita apenas com representantes, e não os representados. Dessa forma a percepção mostrada, ao longo das discussóes, refere-se apenas ao pequeno grupo de pessoas que participam das reuniões e ações das duas associações, excluindo-se o entendimento e interpretação dos representados na mediação entre comunidade e poder público local. 
Buscou-se pesquisar organizações que apresentassem características semelhantes. Mesmo que os bairros que elas representam apresentem características distintas, as duas associações são colocadas como exemplo de atuação diante dos atores entre os quais se verificou inicialmente a situação das associações cadastradas na Receita Federal. Dessa forma, favoreceram a realização de um estudo de caso, mas não foram contempladas pela pesquisa outras associações, sejam elas informais ou, atualmente, inativas.

Diante das contribuições e limitações deste estudo, é possível traçar novas possibilidades para estudos sobre associativismo de bairro no município estudado: (i) caracterização de associações formais não atuantes; (ii) caracterização de associações informais; (iii) investigações sobre a percepção da comunidade acerca do associativismo; (iv) associações em espaços de participação institucionalizada, como Conselhos Gestores de Políticas Públicas; (v) ligações entre religião e lideranças comunitárias; e (iv) relação entre associações e o poder legislativo, não citado durante a coleta de dados.

\section{REFERENCIAS}

Abers, R., Serafim, L., \& Tatagiba, L. (2014). Repertórios de interação Estado sociedade em um estado heterogêneo: a experiência da era Lula. Dados, 57(2), 325-357.

Abers, R., \& Bülow, M. V. (2011). Movimentos sociais na teoria e na prática: como estudar o ativismo através da fronteira entre Estado e sociedade? Sociologias, 13, 52-84.

Alencar, E., Murad, B. T. M., Lisboa, J. M. M., Cimino, P. C. M., Ribeiro, J. C. A.. (1996). Associações comunitárias e participação social: um estudo de caso no sul de Minas Gerais. Cadernos de Administração Rural, 8(1), 1-11.

Amâncio, J. M. (2013). Dinâmicas políticas microterritoriais: organizaçóes comunitárias e acesso às políticas públicas na periferia de São Paulo (Tese de doutorado) Instituto de Filosofia e Ciências Humanas da Universidade Federal de Campinas, Campinas, SP, Brasil.

Avritzer, L. (2007). Sociedade civil, instituições participativas e representação: da autorização à legitimidade da ação. Dados, 50(3), 443-464.

Avritzer, L. (2012). Sociedade civil e Estado no Brasil: dda autonomia à interdependência política. Opinião Pública, 18(2), 383-398.

Baiocchi, G., Heller, P. \& Silva, M. K. (2008). Making space for civil society: institutional reforms and local democracy in Brazil. Social Forces, 86, 911-935.

Bardin, L. (2002). Análise de conteúdo. Lisboa: Edições 70.

Braun, V., \& Clarke, V. (2006). Using thematic analysis in psychology. Qualitative Research in Psychology, 3(2), 77-101.

CGU. Controladoria Geral da União. (2014). Acesso à informação: Governo Federal. Recuperado de http:// www.acessoainformacao.gov.br/. Acesso em: 10 nov. de 2016.

Cortes, S. V., Silva, M. K. (2010). Sociedade civil, instituições e atores estatais: interdependência e condicionantes da atuação de atores sociais em fóruns participativos. Estudos de Sociologia, 15(29), 425-444.

Costa, S. (1994). Esfera pública, redescoberta da sociedade civil e movimentos sociais no Brasil: uma abordagem tentativa. Novos Estudos, 38, 38-52.

Dagnino, E. (2004). Construção democrática, neoliberalismo e participação: os dilemas da confluência perversa. Politica \& Sociedade, 1(5), 137-161.

Dias, R. P. (2009). Bob Jessop e a abordagem relacional-estratégica. Cadernos Cemarx, 6, 133-152.

Duarte, A. L. (2008). "Em busca de um lugar no mundo": movimentos sociais e política na cidade de São Paulo nas décadas de 1940 e 50. Estudos Históricos, 21(42), 195-219.

Elias, N. (2001). A sociedade da corte: investigação sobre a sociologia da realeza e da aristocracia de corte. Rio de Janeiro: Jorge Zahar.

Fontes, P. (2013). Trabalhadores e associativismo urbano no governo Jânio Quadros em São Paulo (1953-1954). Revista Brasileira de História, 33(66), 71-94. 
Gil, A. C. (1999). Métodos e técnicas de pesquisa social. (5a. ed.). São Paulo: Atlas.

Gohn, M. da G. (2010). Morumbi: o contraditório bairro-região de São Paulo. Caderno CRH, 23(59), 267-281

Gurza-Lavalle, A. (1999). Crítica ao modelo da nova sociedade civil. Lua Nova, São Paulo, 47, 121-135.

Gurza-Lavalle, A., Castello, G., \& Bichir, R. M. (2007). Protagonistas na sociedade civil: redes e centralidades de organizações civis em São Paulo. Dados, 50(3), 465-498.

IBGE. Instituto Brasileiro de Geografia e Estatística (2004). As fundações privadas e associações sem fins lucrativos no Brasil 2002, 2004. Recuperado de http://biblioteca.ibge.gov.br/visualizacao/livros/liv5428.pdf. Acesso em: 10 nov. de 2016.

IBGE. Instituto Brasileiro de Geografia e Estatística. (2008). As fundações privadas e associações sem fins lucrativos no Brasil 2005. Recuperado de http://www.ibge.gov.br/home/estatistica/economia/fasfil/2005/fasfil.pdf. Acesso em: 10 nov. de 2016.

IBGE. Instituto Brasileiro de Geografia e Estatística. (2012). As fundações privadas e associações sem fins lucrativos no Brasil 2010. Recuperado de ftp://ftp.ibge.gov.br/Fundacoes_Privadas_e_Associacoes/2010/fasfil.pdf. Acesso em: 10 nov. de 2016.

IBGE. Instituto Brasileiro de Geografia e Estatística. (2015). IBGE cidades: Lavras. Recuperado de http://www.cidades.ibge.gov.br/painel/painel.php?lang=\&codmun=313820\&search=||infogr\%E1ficos:dados-gerais-do-munic\%EDpio. Acesso em: 10 nov. de 2016.

Jessop, B. (1982). The capitalist State: Marxist theories and methods. Oxford: M. Robertson.

Jessop, B. (1985). Nicos Poulantzas: Marxist theory and political strategy. Oxford: MacMillan.

Marques, E. (2007). Os mecanismos relacionais. Revista Brasileira de Ciências Sociais, 22(64), 157-161.

Montaño, C. (2003). Terceiro setor e questão social: crítica ao padrão emergente de intervenção social. 2.ed. São Paulo: Cortez.

Moura, J. T. V., Silva, M. K. (2008). Atores sociais em espaços de ampliação da democracia: as redes sociais em perspectiva. Revista de Sociologia e Política, 16, 43-55.

Ramos, L. C. S. (2005). A sociedade civil em tempos de globalização: uma perspectiva neogramsciana (Dissertação de mestrado). Pontifícia Universidade Católica do Rio de Janeiro, RJ.

Putnam, R. D. (1995). Bowling alone: America's declining social capital. Journal of Democracy, 6(1), 65-77.

Tarrow, S. (1997). El poder em movimento:los movimentos sociales, la acción colectiva y la política. Madrid: Alianza.

Tilly, C. (2006). Regimes and repertoires.Chicago: University of Chicago.

Warren, M. (2001). Democracy and Association. Princeton: Princeton University.

\section{Notas}

i A vertente ou matriz neotocqueviliana concebe a existência de uma sociedade civil ativa como determinante para a consolidação democrática, baseada no conceito de capital social de Putnam (1995). Essa perspectiva é duramente criticada, principalmente pelos teóricos que tratam da sociologia relacional, por criar uma dualidade e um antagonismo entre sociedade civil (positividade) e o Estado (negatividade), semelhante à crítica feita aos escritos sobre participação no Brasil anteriores à Constituição Federal de 1988), uma discussão completa pode ser vista em Warren (2001).

\section{BY-NC-ND}

